\title{
Comparison of Efficacy and Safety of Azilsartan and Olmesartan in Patients With Essential Hypertension
}

\section{A Randomized and Prospective Study (CANZONE Study)}

\author{
Yuhei Shiga, ${ }^{1,2,3,4,5}$ MD, Shin-ichiro Miura, ${ }^{1,6}$ MD, Kota Motozato, ${ }^{1,5}$ MD, \\ Kenji Norimatsu, ${ }^{1} \mathrm{MD}$, Masaya Yano,${ }^{1,3} \mathrm{MD}$, Yuka Hitaka, ${ }^{1,2} \mathrm{MD}$, Sen Adachi, ${ }^{1} \mathrm{MD}$, \\ Takashi Kuwano, ${ }^{1} \mathrm{MD}$, Ken Inoue, ${ }^{2} \mathrm{MD}$, Asao Inoue, ${ }^{2} \mathrm{MD}$, \\ Kazuaki Fujisawa, ${ }^{3} \mathrm{MD}$, Tetsuro Shirotani, ${ }^{4} \mathrm{MD}$, Takaaki Kusumoto, ${ }^{5} \mathrm{MD}$, \\ Munehito IDEISHI, ${ }^{1} \mathrm{MD}$, and Keijiro SAKU, ${ }^{1,2} \mathrm{MD}$
}

\begin{abstract}
SUMMARY
Many patients still have high blood pressure (BP) after treatment with angiotensin II type $1\left(\mathrm{AT}_{1}\right)$ receptor blockers (ARBs). We compared the efficacy and safety of azilsartan to those of olmesartan in a prospective randomized clinical trial. Sixty-four hypertensive patients who were treated with ARBs other than azilsartan and olmesartan were enrolled in this study. We randomly assigned patients to changeover from their prior ARBs to either azilsartan or olmesartan, and followed the patients for 3 months. Systolic BP (SBP) in the azilsartan group was significantly decreased at 3 months, and diastolic BP (DBP) and pulse rate (PR) in the olmesartan group showed significant reductions after 3 months. There were no significant differences in $\triangle \mathrm{SBP}, \triangle \mathrm{DBP}$, or $\Delta \mathrm{PR}(\Delta=$ the value at 3 months minus the value at 0 months $)$ between the groups. Serum levels of creatinine $(\mathrm{Cr})$, uric acid (UA), and potassium $(\mathrm{K})$ in the azilsartan group significantly increased after 3 months. While the changes in $\mathrm{Cr}$, UA, and $\mathrm{K}$ were within the respective normal ranges, $\triangle \mathrm{SBP}$ was positively associated with $\Delta \mathrm{Cr}$ in the azilsartan group. In conclusion, there was no difference in the depressor effects of azilsartan and olmesartan, and there were no serious changes in biochemical parameters with azilsartan and olmesartan. (Int Heart J 2017; 58: 416-421)
\end{abstract}

Key words: Blood pressure, Angiotensin II type 1 receptor blocker, Uric acid

$\mathrm{S}$ even types of angiotensin II type $1\left(\mathrm{AT}_{1}\right)$ receptor blockers (ARBs) have been

developed and are available for clinical use in Japan. ${ }^{1)}$ ARBs is effective in the treatment of cardiovascular disorders, including hypertension and heart failure. ${ }^{1,2}$ ARBs have been reported to have class-specific (common) and moleculespecific (differential) effects in basic experimental studies. ${ }^{3)}$ We have proposed that small differences in the molecular structures of ARBs could lead to differences in their abilities to influence the $\mathrm{AT}_{1}$ receptor. ${ }^{3,4)}$

Azilsartan is the newest ARB to be approved for clinical use in Japan, and has a significant blood pressure (BP)-lowering effect, although the next generation ARBs could be a significant breakthrough in the field of cardiovascular medicine. ${ }^{5 \text { ) }}$ Azilsartan medoxomil and azilsartan have been reported to have greater antihypertensive effects than other ARBs. ${ }^{6-9)}$ Azilsartan has been shown to bind tightly to and dissociate slowly from $\mathrm{AT}_{1}$ receptors. ${ }^{10)}$ Therefore, we hypothesized that the depressor effect of azilsartan may be superior to those of other ARBs in patients with hypertension (HTN). In this study, we performed a changeover from their prior ARBs to azilsartan or olmesartan in patients with hypertension, and compared the efficacy and safety of azilsartan to those of olmesartan in a prospective randomized clinical trial.

\section{MeTHODS}

Study design: Sixty-four hypertensive patients who were treated with ARBs except for azilsartan and olmesartan were enrolled. We applied a changeover of ARBs, where patients were prospectively and randomly switched from their prior ARBs, except for azilsartan and olmesartan, to azilsartan (AZ group, $20 \mathrm{mg} /$ day) or olmesartan (OL group, $20 \mathrm{mg} /$ day), and followed the patients for 3 months. Patients with uncontrolled BP were defined as $\geq 140 / 90 \mathrm{mmHg}$ [ $\geq 130 / 80 \mathrm{mmHg}$ in patients with diabetes mellitus (DM) and/or chronic kidney disease (CKD)] under ARB therapy according to the Japanese Society of Hypertension Guidelines for the Management of Hypertension (JSH 2009). ${ }^{11)}$ We excluded patients with sec-

From the ${ }^{1}$ Department of Cardiology, Fukuoka University School of Medicine, ${ }^{2}$ Inoue Hospital, ${ }^{3}$ Fujisawa Clinic, Fukuoka, ${ }^{4}$ Shirotani Hospital, ${ }^{5}$ Division of Cardiology, Izumi General Medical Center, Kagoshima, and ${ }^{6}$ Department of Molecular Cardiovascular Therapeutics, Fukuoka University School of Medicine, Fukuoka, Japan.

Address for correspondence: Shin-ichiro Miura, MD, Department of Cardiology, Fukuoka University School of Medicine, 7-45-1 Nanakuma, Jonan-ku, Fukuoka 8140180, Japan. E-mail: miuras@ cis.fukuoka-u.ac.jp

Received for publication June 16, 2016. Revised and accepted September 23, 2016.

Released in advance online on J-STAGE May 12, 2017.

All rights reserved by the International Heart Journal Association. 
ondary HTN, acute coronary syndrome within the previous 6 months, pregnancy, or a history of allergy to azilsartan or olmesartan. In addition, 8 patients withdrew because they had hypotension ( 2 and 1 in the AZ and OL groups, respectively) or high BP (3 and 2 in the AZ and OL groups, respectively) during the study period. Therefore, we finally analyzed 56 hypertensive patients ( 28 and 28 in the AZ and OL groups, respectively). In the AZ group, patients changed from candesartan ( $n$ $=5$, average dose $6 \pm 2 \mathrm{mg} /$ day $)$, valsartan $(n=6,73 \pm 16 \mathrm{mg} /$ day), telmisartan ( $n=12,35 \pm 9 \mathrm{mg} /$ day $), \operatorname{losartan}(n=2,45 \pm$ $11 \mathrm{mg} /$ day $)$, or irbesartan $(n=3,100 \pm 0 \mathrm{mg} /$ day $)$. The patients in the OL group changed from candesartan $(n=4$, average dose $6 \pm 2 \mathrm{mg} /$ day $)$, valsartan $(n=7,74 \pm 15 \mathrm{mg} /$ day $)$, telmisartan $(n=7,37 \pm 8 \mathrm{mg} /$ day $), \operatorname{losartan}(n=5,45 \pm 11 \mathrm{mg} /$ day), or irbesartan ( $n=5,110 \pm 55 \mathrm{mg} /$ day $)$. The primary endpoint was the depressor effect of BP in the AZ and OL groups. Secondary endpoints were the changes in biochemical parameters in blood and urine between 0 and 3 months in the $\mathrm{AZ}$ and OL groups. The protocol in this study was approved by the ethics committee of Fukuoka University Hospital (\#12-4-02) and registered under UMIN000016249. All of the subjects provided written informed consent to participate.

Evaluation of clinical parameters: Office systolic BP (SBP), diastolic $\mathrm{BP}(\mathrm{DBP})$, and pulse rate (PR) were obtained at 0,1 , 2 , and 3 months. BP was determined as the mean of two measurements obtained in an office setting by the conventional cuff method using a mercury sphygmomanometer after at least 5 minutes of rest. We also measured body weight (BW) and blood and urinary levels of biochemical parameters at baseline (0 months) and after 3 months. All of the blood and urinary samples were collected in the morning after the patients had fasted overnight. Data regarding serum levels of biochemical parameters, such as urea nitrogen $(\mathrm{UN})$, creatinine $(\mathrm{Cr})$, sodium $(\mathrm{Na})$, potassium $(\mathrm{K})$, high-density lipoprotein-cholesterol (HDL-C), low-density lipoprotein-cholesterol (LDL-C), triglycerides (TG), uric acid (UA), fasting plasma glucose (FPG), hemoglobin A1c (HbA1c), and amino-terminal pro-brain natriuretic peptide (NT-proBNP), and urinary levels of albumin (U-Alb), the ratio of UA to $\mathrm{Cr}$ (U-UA/U-Cr), and fractional excretion of UA (FEUA) were collected. Body mass index (BMI) was calculated as weight $(\mathrm{kg}) /$ height $(\mathrm{m})^{2}$.

The characteristics of the patients, with regard to history of HTN, dyslipidemia (DL), diabetes mellitus (DM), hyperuricemia (HU), CKD, coronary artery disease (CAD), smoking status, and medication use were obtained from medical records. Patients who had a current SBP/DBP $\geq 140 / 90 \mathrm{mmHg}$ or who were receiving antihypertensive therapy were considered to have HTN. Patients with LDL-C $\geq 140 \mathrm{mg} / \mathrm{dL}, \mathrm{TG} \geq$ $150 \mathrm{mg} / \mathrm{dL}$, and/or HDL-C $<40 \mathrm{mg} / \mathrm{dL}$, or who were receiving lipid-lowering therapy, were considered to have DL. DM was defined using the American Diabetes Association criteria or the use of a glucose-lowering drug. HU was defined as a serum UA level of $\geq 7.0 \mathrm{mg} / \mathrm{dL}$ or the use of uric acid-lowering drugs.

Statistical analysis: Statistical analysis was performed using the Stat View statistical software package (Stat View 5; SAS Institute Inc., Cary, NC, USA). Data are shown as the mean \pm standard deviation (SD). Categorical and continuous variables were compared between the groups by chi-square analysis and unpaired $t$-test, respectively. Time course changes were analyzed by the paired $t$-test. The Spearman rank correlation coef- ficient was used to evaluate associations between the parameters. A value of $P<0.05$ was considered significant.

\section{Results}

Patient characteristics in the $\mathbf{A Z}$ and $\mathbf{O L}$ groups: Table I shows the characteristics of the 56 patients in the AZ and OL groups. There were no differences in age, gender, BMI, or medications between the groups. In addition, we did not change these medications throughout the study period.

Time courses of $B P$ and $P R$ in the $A Z$ and $O L$ groups: The time courses of $\mathrm{BP}$ and $\mathrm{PR}$ in the $\mathrm{AZ}$ and $\mathrm{OL}$ groups are shown in Figure 1. In the AZ group, SBP was significantly reduced after 3 months compared with 0 months (from $132 \pm 12$ to $127 \pm 11 \mathrm{mmHg}$ ). $\mathrm{DBP}$ (from $77 \pm 8$ to $74 \pm 8 \mathrm{mmHg}$ ) and PR (from $76 \pm 9$ to $72 \pm 8 \mathrm{bpm}$ ) after 3 months in the OL group were significantly lower than those at 0 months. In the azilsartan group, the $\%$ patients who reached the target BP at 12 weeks (79\%) was higher than that at 0 weeks (61\%), but not significantly. In addition, the \% patients at 12 weeks (64\%) was not different from that at 0 weeks $(50 \%)$ in the olmesartan group.

Changes in SBP, DBP, and PR in the AZ and OL groups: The changes in SBP, DBP, and PR from 0 to 3 months ( $\Delta=$ value at 3 months minus the value at 0 months) are shown in Figure 2. There were no differences in $\triangle \mathrm{SBP}, \triangle \mathrm{DBP}$, or $\triangle \mathrm{PR}$ between the $\mathrm{AZ}$ and OL groups.

Changes in biochemical parameters: As shown in Table II, there were no significant changes in biochemical parameters, including lipid profile, HbA1c, NT-proBNP, U-Alb, and U-UA/U-Cr. On the other hand, serum $\mathrm{Cr}, \mathrm{K}$, and UA in patients who initially received azilsartan were increased after 3 months (Figure 3).

Associations among $\Delta \mathrm{SBP}, \Delta \mathrm{Cr}$, and $\Delta \mathrm{UA}$ in the $\mathrm{AZ}$ group: There was a significant association between $\Delta \mathrm{SBP}$ and $\Delta \mathrm{Cr}(r$ $=-0.543, P=0.003$ ) (Figure 4A). On the other hand, there were no significant associations between $\triangle \mathrm{SBP}$ and $\triangle \mathrm{UA}(r=$ -0.251, $P=0.198)$ or between $\Delta \mathrm{Cr}$ and $\Delta \mathrm{UA}(r=0.099, P=$ 0.616) (Figure 4B, C).

Table I. Baseline Patient Characteristics

\begin{tabular}{lccc}
\hline & $\begin{array}{c}\text { AZ group } \\
(n=28)\end{array}$ & $\begin{array}{c}\text { OL group } \\
(n=28)\end{array}$ & $\begin{array}{c}P \\
\text { AZ versus OL group }\end{array}$ \\
\hline Age, years & $72 \pm 9$ & $70 \pm 9$ & 0.38 \\
Gender (male), \% & 36 & 50 & 0.29 \\
BMI, kg/m ${ }^{2}$ & $23 \pm 4$ & $25 \pm 4$ & 0.19 \\
Smoking, \% & 32 & 21 & 0.67 \\
DL, \% & 57 & 61 & 0.75 \\
DM, \% & 25 & 25 & 1.00 \\
HU, \% & 11 & 14 & 0.71 \\
CAD, \% & 14 & 21 & 0.54 \\
CKD, \% & 32 & 21 & 0.42 \\
Medications & & & \\
CCB, \% & 61 & 46 & 0.16 \\
$\beta$-Blocker, $\%$ & 21 & 18 & 0.71 \\
$\alpha$-Blocker, $\%$ & 7 & 11 & 0.66 \\
\hline
\end{tabular}

BMI indicates body mass index; DL, dyslipidemia; DM, diabetes mellitus; $\mathrm{HU}$, hyperuricemia; CAD, coronary artery disease; CKD, chronic kidney disease; and CCB, calcium channel blocker. 

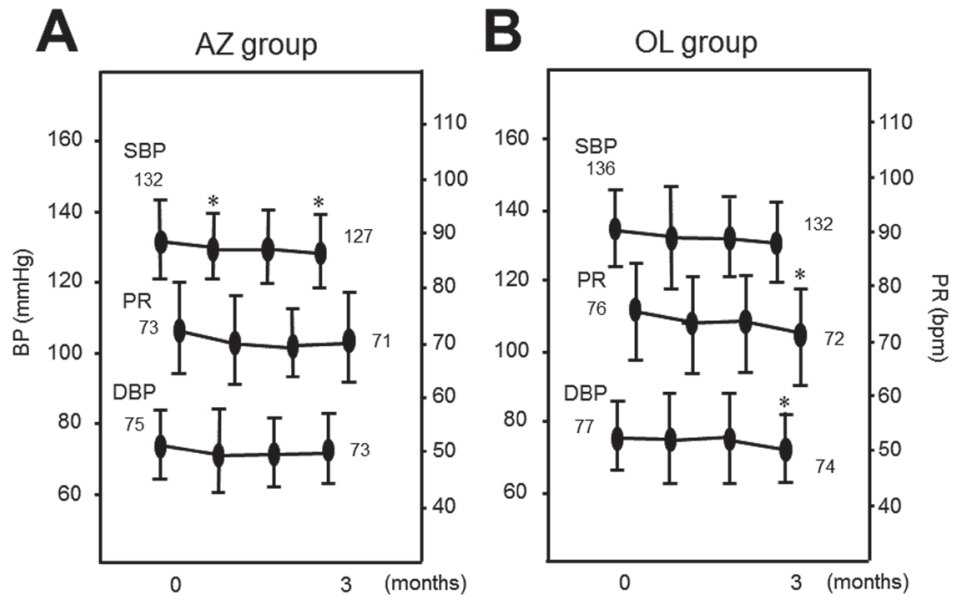

Figure 1. Time courses of SBP, DBP, and PR in the AZ $(n=28)(\mathbf{A})$ and $\mathrm{OL}(n=28)(\mathbf{B})$ groups for 3 months. ${ }^{*} P<0.05$ versus 0 months.

A

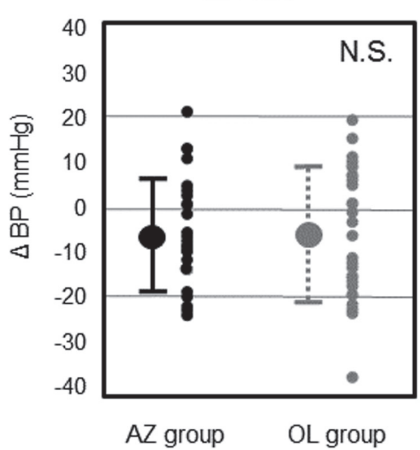

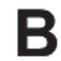

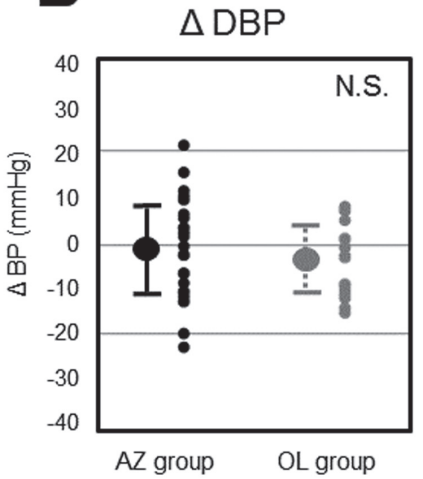

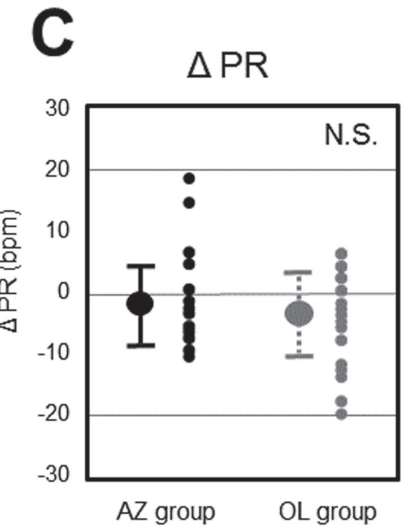

Figure 2. $\triangle \mathrm{SBP}(\mathbf{A}), \triangle \mathrm{DBP}(\mathbf{B})$, and $\triangle \mathrm{PR}(\mathbf{C})$ in the $\mathrm{AZ}(n=28)$ and $\mathrm{OL}(n=28)$ groups for 3 months. $\Delta$ indicates the value at 3 months minus the value at baseline. N.S. indicates not significant.

Table II. Change in Biochemical Parameters in the AZ and OL Groups

\begin{tabular}{|c|c|c|c|c|c|c|}
\hline & \multicolumn{3}{|c|}{ AZ group $(n=28)$} & \multicolumn{3}{|c|}{ OL group $(n=28)$} \\
\hline & 0 months & 3 months & $\begin{array}{c}P \\
0 \text { versus } 3 \text { months }\end{array}$ & 0 months & 3 months & $\begin{array}{c}P \\
0 \text { versus } 3 \text { months }\end{array}$ \\
\hline $\mathrm{UN}, \mathrm{mg} / \mathrm{dL}$ & $16.9 \pm 5.7$ & $17.5 \pm 5.3$ & 0.50 & $15.8 \pm 4.5$ & $15.7 \pm 4.3$ & 0.97 \\
\hline $\mathrm{Na}, \mathrm{mEq} / \mathrm{L}$ & $142 \pm 3$ & $142 \pm 2$ & 0.78 & $142 \pm 2$ & $142 \pm 2$ & 0.70 \\
\hline $\mathrm{TG}, \mathrm{mg} / \mathrm{dL}$ & $151 \pm 124$ & $134 \pm 70$ & 0.38 & $130 \pm 65$ & $129 \pm 79$ & 0.97 \\
\hline LDL-C, mg/dL & $107 \pm 27$ & $110 \pm 26$ & 0.26 & $110 \pm 23$ & $106 \pm 22$ & 0.61 \\
\hline HDL-C, mg/dL & $56 \pm 17$ & $58 \pm 20$ & 0.27 & $58 \pm 165$ & $9 \pm 16$ & 0.41 \\
\hline $\mathrm{FPG}, \mathrm{mg} / \mathrm{dL}$ & $107 \pm 26$ & $104 \pm 28$ & 0.50 & $117 \pm 38$ & $108 \pm 23$ & 0.12 \\
\hline $\mathrm{HbA} 1 \mathrm{c}, \%$ & $5.9 \pm 0.7$ & $5.9 \pm 0.7$ & 0.53 & $6.1 \pm 0.7$ & $6.0 \pm 0.7$ & 0.31 \\
\hline NT-pro BNP, pg/mL & $169 \pm 173$ & $198 \pm 226$ & 0.76 & $213 \pm 342$ & $221 \pm 403$ & 0.60 \\
\hline $\mathrm{U}-\mathrm{Alb}, \mathrm{mg} / \mathrm{g} \cdot \mathrm{Cr}$ & $44 \pm 87$ & $33 \pm 62$ & 0.50 & $25 \pm 37$ & $24 \pm 39$ & 0.99 \\
\hline U-UA/U-Cr & $0.5 \pm 0.2$ & $0.5 \pm 0.2$ & 0.97 & $0.5 \pm 0.2$ & $0.5 \pm 0.2$ & 0.66 \\
\hline FEUA, \% & $8.3 \pm 3.0$ & $7.9 \pm 2.9$ & 0.52 & $9.1 \pm 4.0$ & $9.4 \pm 5.9$ & 0.78 \\
\hline
\end{tabular}

UN indicates urea nitrogen; Na, sodium; TG, triglycerides; LDL-C, low density lipoprotein cholesterol; HDL-C, high density lipoprotein cholesterol; FPG, fast plasma glucose; HbAlc, hemoglobin Alc; BNP, brain natriuretic peptide; U-Alb, urinary albumin; and FEUA, fractional excretion of uric acid. 

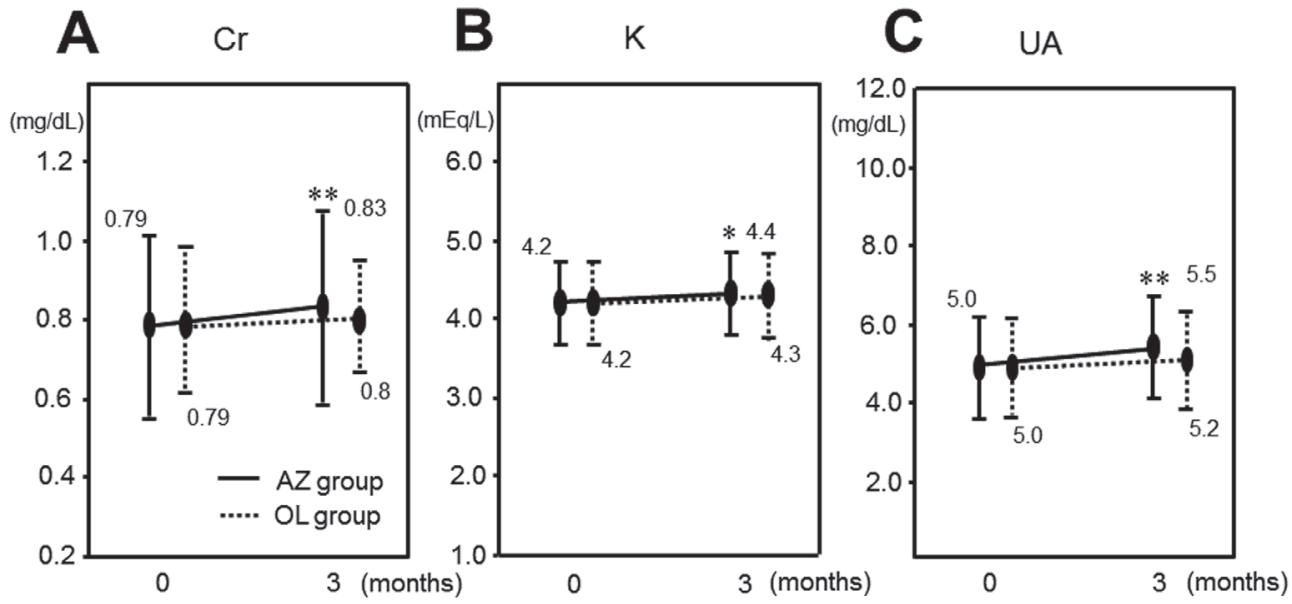

Figure 3. Changes in serum $\mathrm{Cr}(\mathbf{A}), \mathrm{K}(\mathbf{B})$, and $\mathrm{UA}(\mathbf{C})$ in the $\mathrm{AZ}(n=28$, solid lines) and $\mathrm{OL}(n=28$, dotted lines) groups. ${ }^{*} \mathrm{P}<0.05,{ }^{* *} \mathrm{P}<0.01$ versus 0 months.

A

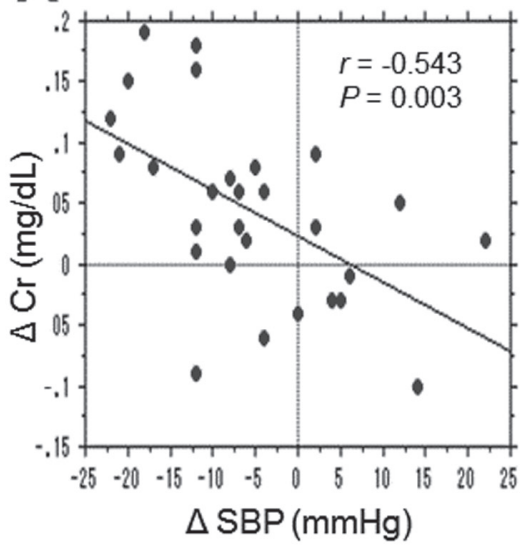

B

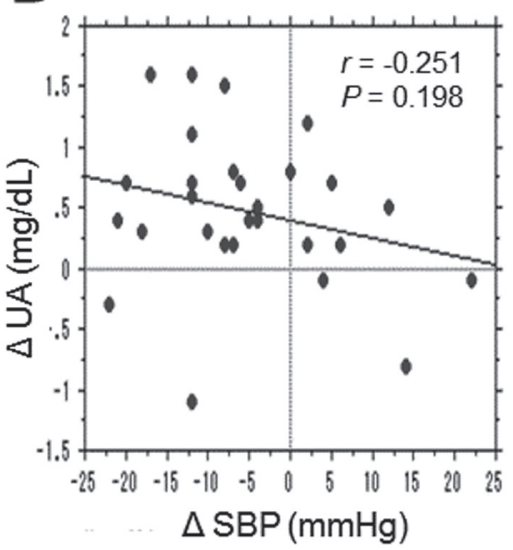

C

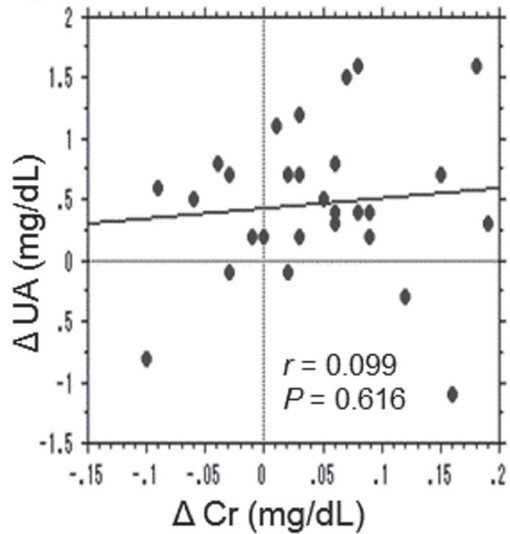

Figure 4. Associations between $\Delta \mathrm{SBP}$ and $\Delta \mathrm{Cr}(\mathbf{A}), \Delta \mathrm{SBP}$ and $\Delta \mathrm{UA}(\mathbf{B})$, and $\Delta \mathrm{Cr}$ and $\Delta \mathrm{UA}(\mathbf{C})$ in the $\mathrm{AZ}$ group. $\Delta$ indicates the value at 3 months minus the value at baseline.

\section{DisCUSSION}

In the present study, the depressor effect in the AZ group was not significantly different from that in the OL group, and there were no serious differences in the levels of $\mathrm{Cr}, \mathrm{K}$, and UA under treatment with azilsartan and olmesartan, although these levels significantly increased in the AZ group.

Azilsartan has been reported to have greater antihypertensive effects than olmesartan in patients with hypertension ${ }^{8)}$ or prediabetes mellitus and type $2 \mathrm{DM}^{.12}$ In these studies, highdoses of azilsartan ( $40 \mathrm{mg} /$ day, equivalent to azilsartan medoxomil $80 \mathrm{mg} /$ day) and olmesartan (40 mg/day) were used, ${ }^{8,12)}$ whereas we used mid-range doses of azilsartan $(20 \mathrm{mg} /$ day $)$ and olmesartan (20 mg/day). Various doses of olmesartan (10$40 \mathrm{mg} / \mathrm{day}$ ) reduced angiotensin II and aldosterone levels and left ventricular mass index more effectively than azilsartan in hypertensive outpatients who were clinically stable after cardiac surgery. ${ }^{13)}$ Thus, the results of comparisons of the beneficial effects of azilsartan and olmesartan were not consistent, and the studies included patients with different backgrounds including the doses of azilsartan and olmesartan. The depressor effect in the AZ group in the present study was not significantly different from that in the OL group and further studies will be needed to resolve this issue.

BP control is a powerful strategy for conferring remarkable clinical benefits with regard to cardiovascular and renal protection. ${ }^{14-16)}$ A 2 mmHg reduction in SBP provides a $10 \%$ lower incidence of stroke mortality and about a $7 \%$ lower incidence of mortality from CAD or other vascular causes in middle-aged subjects. ${ }^{17)}$ Since azilsartan reduced SBP by about 5 $\mathrm{mmHg}$, this reduction may provide tremendous clinical benefits, although there was no difference in the reduction of SBP between the $\mathrm{AZ}$ and $\mathrm{OL}$ groups.

In this study, serum $\mathrm{Cr}$ levels in the $\mathrm{AZ}$ group significantly increased after patients switched from their prior ARBs. Azilsartan has a unique moiety, 5-oxo-1, 2, 4 oxadiazole in place of a tetrazole ring, and this significant feature has been reported to induce strong inverse agonism and high affinity for the $\mathrm{AT}_{1}$ receptor compared with other $\mathrm{ARBs} .{ }^{10,18)}$ In addition, $\triangle \mathrm{SBP}$ was significantly and negatively associated with $\Delta \mathrm{Cr}$ in the $\mathrm{AZ}$ group. It is common for $\mathrm{Cr}$ to increase shortly after the initiation of treatment with ARB or with a change to a stronger 
ARB. This response is functional in nature and should be expected based on renal physiology (adaptive effect in response to a reduction in glomerular BP) and its dependence on the renin-angiotensin system to maintain the glomerular filtration rate (GFR). ${ }^{19)}$ Since an early elevation in serum $\mathrm{Cr}$ is associated with improved long-term renal outcomes, the slight increase in $\mathrm{Cr}$ in this study should not cause concern. Azilsartan also significantly increased serum $\mathrm{K}$ levels. Although the reason for this result is not clear and might be the same as the mechanism of the slight increase in $\mathrm{Cr}$, none of the patients received new medications or changed the doses of their medications during the 3 months of the study.

In this study, UA levels increased after patients switched from their prior ARBs to azilsartan. Losartan and irbesartan have been shown to have uricosuric action via URAT1 and induce a reduction of serum $\mathrm{UA},{ }^{20,21)}$ whereas the effects of azilsartan on serum UA are not clear. Although HU can be classified into 2 types (an overproduction of UA and a decrease in the urinary excretion of UA), ${ }^{22)} \mathrm{U}-\mathrm{UA} / \mathrm{U}-\mathrm{Cr}$ did not change after the changeover to azilsartan. The normal UA values at our hospital are 5.0-7.0 mg/dL. Therefore, we divided the patients in the AZ group into 2 groups according to the normal range. ${ }^{23,24)}$ Our "relatively high UA" was defined as UA $>6.0$ $\mathrm{mg} / \mathrm{dL}$, and "relatively low UA" was defined as $6.0 \mathrm{mg} / \mathrm{dL} \geq$ UA. In AZ patients with relatively low UA, although the UA value at 3 months $(5.1 \pm 1.0 \mathrm{mg} / \mathrm{dL})$ was significantly increased compared with the value at baseline $(4.6 \pm 1.0 \mathrm{mg} / \mathrm{dL})$ $(P<0.01)$, the value was still within the normal range. In addition, there were no significant changes in UA between baseline $(6.9 \pm 0.4 \mathrm{mg} / \mathrm{dL})$ and at 3 months $(7.1 \pm 0.8 \mathrm{mg} / \mathrm{dL})$ in $\mathrm{AZ}$ patients with relatively high UA $(P=0.54)$. Thus, azilsartan had only a slight negative influence on serum UA, although we cannot clearly explain the mechanism of the increase in UA in the AZ group. Since the serum UA level is regulated by GFR, and since $\mathrm{Cr}$ in the $\mathrm{AZ}$ group significantly decreased after 3 months, it is possible that an increase in serum UA in the AZ group may reflect a decrease in GFR.

This study has two important limitations. First, the sample size is relatively small, which limits our ability to determine significance. Second, we applied a changeover, with switching from various ARBs to azilsartan or olmesartan. A crossover study would be preferable. However, the patients were divided into the two groups randomly, and this may have minimized any difference in BP.

In conclusion, the depressor effect of azilsartan was not different from that of olmesartan, and there were no serious changes in biochemical parameters under treatment with azilsartan and olmesartan, although the levels of $\mathrm{Cr}, \mathrm{K}$ and UA significantly increased in patients treated with azilsartan.

\section{Disclosures}

Conflicts of interest: K.S. is a Chief Director and S.M. is a Director of NPO Clinical and Applied Science, Fukuoka, Japan. K.S. has an Endowed Department of "Department of Molecular Cardiovascular Therapeutics" supported by MSD, Co. LTD. S.M. belongs to the Department of Molecular Cardiovascular Therapeutics supported by MSD, Co. LTD.

\section{REFERENCES}

1. Imaizumi S, Miura S, Yahiro E, Uehara Y, Komuro I, Saku K. Class- and molecule-specific differential effects of angiotensin II type 1 receptor blockers. Curr Pharm Des 2013; 19: 3002-8. (Review)

2. Adachi Y, Sakakura K, Wada H, et al. Determinants of left ventricular systolic function improvement following coronary artery revascularization in heart failure patients with reduced ejection fraction (HFrEF). Int Heart J 2016; 57: 565-72.

3. Miura S, Karnik SS and Saku K. Review: angiotensin II type 1 receptor blockers: class effects versus molecular effects. J Renin Angiotensin Aldosterone Syst 2011; 12: 1-7. (Review)

4. Fujino M, Miura S, Kiya Y, et al. A small difference in the molecular structure of angiotensin II receptor blockers induces AT1 receptor-dependent and -independent beneficial effects. Hypertens Res 2010; 33: 1044-52.

5. Ikeda Y, Kumagai H, Motozawa Y, Suzuki J, Komuro I. Next generation ARBs. Going beyond modulation of the renin-angiotensin system. Int Heart J 2015; 56: 585-6.

6. Rakugi H, Enya K, Sugiura K, Ikeda Y. Comparison of the efficacy and safety of azilsartan with that of candesartan cilexetil in Japanese patients with grade I-II essential hypertension: a randomized, double-blind clinical study. Hypertens Res 2012; 35: 552-8.

7. White WB, Weber MA, Sica D, et al. Effects of the angiotensin receptor blocker azilsartan medoxomil versus olmesartan and valsartan on ambulatory and clinic blood pressure in patients with stages 1 and 2 hypertension. Hypertension 2011; 57: 413-20.

8. Bakris GL, Sica D, Weber M, et al. The comparative effects of azilsartan medoxomil and olmesartan on ambulatory and clinic blood pressure. J Clin Hypertens 2011; 13: 81-8.

9. Sica D, White WB, Weber MA, et al. Comparison of the novel angiotensin II receptor blocker azilsartan medoxomil vs valsartan by ambulatory blood pressure monitoring. J Clin Hypertens 2011; 13: 467-72.

10. Ojima $\mathrm{M}$, Igata $\mathrm{H}$, Tanaka $\mathrm{M}$, et al. In vitro antagonistic properties of a new angiotensin type 1 receptor blocker, azilsartan, in receptor binding and function studies. J Pharmacol Exp Ther 2011; 336: 801-8.

11. Ogihara T, Kikuchi K, Matsuoka H, et al; Japanese Society of Hypertension Committee. The Japanese Society of Hypertension Guidelines for the Management of Hypertension (JSH 2009). Hypertens Res 2009; 32: 3-107.

12. White WB, Cuadra RH, Lloyd E, Bakris GL, Kupfer S. Effects of azilsartan medoxomil compared with olmesartan and valsartan on ambulatory and clinic blood pressure in patients with type 2 diabetes and prediabetes. J Hypertens 2016; 34: 788-97.

13. Sezai A, Osaka S, Yaoita H, et al. Changeover trial of azilsartan and olmesartan comparing effects on the renin-angiotensin-aldosterone system in patients with essential hypertension after cardiac surgery (CHAOS Study). Ann Thorac Cardiovasc Surg 2016; 22: 161-7.

14. ALLHAT Officers and Coordinators for the ALLHAT Collaborative Research Group. Major outcomes in high-risk hypertensive patients randomized to angiotensin-converting enzyme inhibitor or calcium channel blocker vs diuretic: The Antihypertensive and Lipid-Lowering Treatment to Prevent Heart Attack Trial (ALLHAT). JAMA 2002; 288: 2981-97.

15. Staessen JA, Wang JG, Thijs L. Cardiovascular protection and blood pressure reduction: a meta-analysis. Lancet 2001; 358: 1305-15.

16. Yamagata K, Ishida K, Sairenchi T, et al. Risk factors for chronic kidney disease in a community-based population: a 10-year follow-up study. Kidney Int 2007; 71: 159-66.

17. Lewington S, Clarke R, Qizilbash N, Peto R, Collins R; Prospective Studies Collaboration. Age-specific relevance of usual blood pressure to vascular mortality: A meta-analysis of individual data for one million adults in 61 prospective studies. Lancet 2002; 360: 1903-13

18. Miura S, Okabe A, Matsuo Y, Karnik SS, Saku K. Unique binding 
behavior of the recently approved angiotensin II receptor blocker azilsartan compared with that of candesartan. Hypertens Res 2013; 36: 134-9.

19. Epstein BJ. Elevations in serum creatinine concentration: concerning or reassuring? Pharmacotherapy 2004; 24: 697-702.

20. Elliott WJ, Calhoun DA, DeLucca PT, Gazdick LP, Kerns DE, Zeldin RK. Losartan versus valsartan in the treatment of patients with mild to moderate essential hypertension: data from a multicenter, randomized, double-blind, 12-week trial. Clin Ther 2007; 23: 1166-79.

21. Iwanaga T, Sato M, Maeda T, Ogihara T, Tamai I. Concentrationdependent mode of interaction of angiotensin II receptor blockers with uric acid transporter. J Pharmacol Exp Ther 2007; 320: 211 7.
22. Ohta Y, Tsuchihashi T and Kiyohara K. Usefulness of conventional methods of the classification of hyperuricemia in hypertensive patients with hyperuricemia. Gout and Nucleic Acid Metabolism 2012; 36: 9-13.

23. Shiga Y, Miura S, Mitsutake R, et al. Efficacy and safety of a single-pill fixed-dose combination of high-dose telmisartan/hydrochlorothiazide in patients with uncontrolled hypertension. J Renin Angiotensin Aldosterone Syst 2012; 13: 394-400.

24. Shiga Y, Miura S, Norimatsu K, et al. Efficacy and safety of combination therapy of high-dose losartan and hydrochlorothiazide in patients with hypertension. J Renin Angiotensin Aldosterone Syst 2015; 16: 1078-84 